\title{
Criterio normativo y uso general culto en el Diccionario panhispánico de dudas*
}

\author{
$M^{a}$ ELENA A ZOFRA SIERRA \\ Universidad Carlos III de Madrid
}

El influjo del latín sobre el castellano, como lengua de cultura, ha sido muy fuerte en todas las épocas de la historia de nuestra lengua. El resultado es la existencia hoy de un gran caudal de latinismos simples y expresiones latinas, cuyo uso es fuente de dudas y vacilaciones entre los hablantes cultos. Incluso un buen conocimiento de la lengua latina, a veces, no resulta una ventaja sino un inconveniente, pues las reglas morfosintácticas latinas no son siempre las preferidas en el proceso de adaptación de estos préstamos cultos en español.

Hasta ahora, las únicas recomendaciones normativas con las que el hablante podía contar eran las que proporcionaban las sucesivas ediciones del $D R A E$. Su utilidad era relativa, pues, si bien se trata de piezas léxicas, para las que el diccionario puede indicar grafías y acepciones, sin embargo no resultaba igualmente útil para el uso de estos términos dentro de sintagmas u oraciones completas. Por su parte, el Esbozo (1973), utilizado por los hablantes cultos como referencia, a pesar de su voluntad expresa de no constituir norma, ${ }^{1}$ es sumamente vago en sus indicaciones con respecto a los latinismos, como veremos.

Era necesaria, por tanto, una obra de carácter normativo, que permitiera a los hablantes resolver dudas de distinto tipo: de pronunciación, morfológicas, sintácticas y semánticas. La reciente aparición del Diccionario panhispánico de dudas (en adelante, DPD), una obra con voluntad normativa, ${ }^{2}$ ha venido a llenar este vacío, con sus recomendaciones sobre todos los problemas que el uso de latinismos y locuciones latinas plantea en español. El DPD reconoce el carácter relativo y cambiante de la norma y afirma que en sus propuestas ha tenido muy en cuenta la realidad del cambio lingüístico y no se ha conformado con «repetir juicios heredados de la tradición normativa», sino que ha analizado la pervivencia y extensión real de los usos comentados para ofrecer «soluciones y recomendaciones fundadas en la realidad lingüística presente» (p. XIV). La norma se basa en la expresión culta de nivel formal, la que constituye el español estándar: «En los juicios y recomendaciones sobre los fenómenos analizados se conjugan, ponderadamente, los criterios de vigencia, de extensión y de frecuencia en el uso general culto» (p. XV). ${ }^{3}$ Esta, como veremos, es su intención, pero en el caso de los latinismos muchas veces se incumple este propósito.

\footnotetext{
* Este trabajo se enmarca en el proyecto de investigación CCG06-UC3M/HUM-0746, financiado por la Comunidad Autónoma de Madrid y la Universidad Carlos III.

${ }^{1}$ Ya en la Advertencia con que se abre la obra, destacado en versales, podemos leer: «POR SU CARÁCTER, PUES, DE SIMPLE EL PROYECTO, EL PRESENTE Esbozo CARECE DE TODA VALIDEZ NORMATIVA».

2 «El DPD es un diccionario normativo en la medida en que sus juicios y recomendaciones están basados en la norma que regula hoy el uso correcto de la lengua española» (p. XIII).

${ }^{3}$ La negrita en esta cita es nuestra.
}

$\mathrm{M}^{\mathrm{a}}$ Elena Azofra SiERra, «Criterio normativo y uso general culto en el Diccionario panhispánico de dudas», Revista de Lexicografia, XIII (2007), pp. 7-16. 
Nos proponemos analizar, en este estudio, los criterios que se han aplicado en el tratamiento de estos términos, así como las implicaciones que tienen, desde el punto de vista léxico y gramatical, en el proceso continuado de incorporación e integración de voces cultas latinas en la historia del español.

\section{PeCuliaridad de los latinismos FRente a los préstamos de otras lenguas}

Para ello vamos a destacar, en primer lugar, las características de los latinismos, tan diferentes a los préstamos de otras lenguas. Su peculiaridad consiste en que son préstamos de la lengua de origen, tomada posteriormente como lengua de cultura; por esta circunstancia, a un hablante culto le resultan términos mucho más familiares que los procedentes de lenguas modernas. Sin embargo, debido precisamente a esta cercanía con la lengua de origen y a la impresión de familiaridad que pueden producir en los hablantes, es mucho más difícil deslindar cuándo se produce la transferencia de una lengua a otra, cuándo podemos hablar de términos o expresiones castellanas y no latinas (Azofra 2006). Por otro lado, comparten con otros extranjerismos la fuerza evocadora y prestigiosa, que puede condicionar la elección léxica o su mayor o menor grado de adaptación a los patrones morfosintácticos del español. El DPD propone el reconocimiento de iguales reglas para los latinismos que para el resto de los extranjerismos; aunque esto constituye un apoyo a su integración en nuestra lengua, al suponer que pueden seguir una acomodación a las normas gráficas y morfológicas paralela a las de otros préstamos, no deja de ser una arbitrariedad, al obviar las diferencias sustanciales en estos préstamos de una lengua de superestrato y no de adstrato. ${ }^{4}$ Probablemente estas diferencias son las que encontramos reflejadas en el diccionario, a pesar de su voluntad de acomodar homogéneamente los préstamos de todo tipo.

Para analizar el tratamiento de los latinismos en el $D P D$ y su adecuación a los criterios de uso y a las preferencias de los hablantes, vamos a centrarnos en varias cuestiones: el resalte tipográfico, las recomendaciones de pronunciación y grafía, el grado de integración que refleja su variabilidad morfosintáctica y las reglas de formación de plurales específicamente.

\section{RESALTE TIPOGRÁFICO}

El resalte tipográfico, según el $D P D$, permite diferenciar los «extranjerismos crudos» de los «adaptados». De esta forma, el diccionario presenta la entrada en redonda si se adapta la pronunciación o la grafía, y en cursiva si se conserva la grafía de la lengua original. No vamos a entrar en la cuestión de que los supuestos extranjerismos «adaptados» son a veces mucho más «crudos» y extraños para los hablantes que los calificados como «extranjerismos crudos» (véanse los ejemplos jipi o rocanrol, frente a hippy o rock and roll). Por otro lado, las grafías extranjeras nunca van señaladas con bolaspa, ${ }^{5}$ porque su estructura es la correcta en su idioma original.

No obstante, nada se advierte respecto a los «latinismos crudos», a pesar de que la terminología fue acuñada por Américo Castro precisamente para las palabras de esta procedencia que no

\footnotetext{
${ }^{4}$ El latín ha actuado históricamente sobre el español como lengua de superestrato por su prestigio cultural.

${ }^{5}$ Bolaspa es el neologismo con que el $D P D$ designa el símbolo $\otimes$, elegido para marcar las incorrecciones. En este estudio, reproducimos la bolaspa delante de las formas censuradas por el $D P D$ y utilizamos el asterisco con su valor habitual, para las formas no documentadas.
} 
se habían adaptado a las reglas morfosintácticas del español (por ejemplo, los procedentes de neutros latinos acabados en - um que no han cambiado esta terminación por $-o$ ). Si medimos el grado de asimilación e integración en la lengua prestataria con criterios gramaticales, no podremos calificar como latinismos españoles a la mayoría de las palabras señaladas con esta etiqueta en el $D P D$, pues no se usan como castellanas, sino como latinas, es decir, serían latinismos «crudos» o directamente citas en latín. Sin embargo, el $D P D$ no resalta tipográficamente con cursiva ningún latinismo; la letra redonda parece indicar que se consideran términos castellanos, no latinos, aun cuando en ocasiones encontramos en el artículo correspondiente «expresión latina que se usa...» $(D P D, s . v$. id est). Esto puede llevar a paradojas como encontrar con redonda el término exequátur y con cursiva el término zoom, a pesar de que es mucho más familiar para un hablante culto el segundo. Sorprende que no se haga la misma recomendación de resalte tipográfico para marcar los latinismos. El hablante que construye el sintagma término ad quem es plenamente consciente de estar utilizando una expresión extraña a su lengua, hasta cierto punto «citada» del latín; ad quem funciona como un adjetivo, pero no se ha adaptado al español y eso se nota en la grafía separada o en la invariabilidad respecto al número (decimos en plural términos ad quem), aunque tampoco cabe duda de que ya no es una expresión totalmente latina, pues no decimos términos ad quos. Sin embargo, por ser un préstamo del latín debemos escribirlo con letra redonda, según el $D P D$, y no cursiva. A pesar de ello, y precisamente porque son conscientes de estar citando formas de una lengua de prestigio, muchos hablantes cultos se sienten cómodos escribiendo con cursiva y sin tilde los corpora o los curricula, censurados por el DPD. ${ }^{6}$ Creemos que la recomendación del diccionario contradice el uso culto y no es coherente con otras propuestas.

\section{VARIABILIDAD MORFOSINTÁCTICA Y GRADO DE INTEGRACIÓN}

El grado de integración de los latinismos y expresiones latinas que aparecen en el $D P D$ es muy variable. Parecen perfectamente integradas formas que proceden de expresiones pluriverbales y se escriben en español con grafía simple, como abintestato, etcétera (sustantivo masculino, respetuoso con el género neutro etimológico, a pesar de la terminación), ${ }^{7}$ exabrupto, exlibris o paterfamilias (aunque también se admiten las grafías separadas ex libris o páter familias). A pesar de la grafía simple, no parece muy integrado el adjetivo proindiviso; su invariabilidad, ${ }^{8}$ poco justificada por la forma (sería muy sencillo formar el femenino analógico *proindivisa o los plurales *proindivisos / -as) es una prueba importante de su escasa integración e indica que, a pesar de la grafía simple, se siente como palabra latina. Lo mismo sucede con el sustantivo médium, que puede usarse como masculino o femenino (el / la médium).

La mayoría de las locuciones son invariables en plural y además se escriben con grafía separada aunque el concepto al que se refieran sea unitario: así tenemos locuciones nominales como los casus belli, los post scríptum y locuciones adjetivas como cum laude o ad hoc; el $D P D$ censura los intentos de los hablantes de adaptar estas expresiones a nuestros patrones morfológicos de género o número: ${ }^{\otimes}$ pecatas minutas o ${ }^{\otimes}$ la mea culpa ${ }^{9}$ aparecen con bolaspa (pero el hecho de que aparezcan es prueba de que se ha intentado su acomodación al espa-

\footnotetext{
${ }^{6} \mathrm{El}$ diccionario prefiere los plurales invariables los corpus y los currículum vítae (cf. infra, apartado 5).

${ }^{7}$ Cf. ejemplo del DPD: «infinitos etcéteras»

${ }^{8}$ El ejemplo del $D P D$ es «... las fincas proindiviso que nos dejó mi madre...».

${ }^{9}$ Uso correcto: sing. el mea culpa, pl. los mea culpa.
} 
ñol)..$^{10}$ No parece mayor el grado de integración de locuciones adverbiales como grosso modo, ab initio, contrario sensu, ipso facto, manu militari, motu proprio o ex profeso; el diccionario censura los intentos de los hablantes de hipercaracterizar estas expresiones como locuciones adverbiales anteponiendo una preposición: con bolaspa aparecen así ${ }^{\otimes}$ a grosso modo, ${ }^{\otimes}$ desde ab initio, ${ }^{\otimes}$ a contrario sensu, ${ }^{\otimes}$ de ipso facto, ${ }^{\otimes}$ con manu militari, ${ }^{\otimes}$ delpor motu proprio o de ex profeso, formas que reflejan la tendencia que ya en latín vulgar fue una de las causas del derrumbe del sistema de la declinación latina.

También aparecen censurados en el diccionario los intentos de los hablantes de variar estas expresiones de acuerdo con la morfosintaxis latina. Así sucede, por ejemplo, en ${ }^{\otimes}$ ad honores; el DPD presenta como locución invariable ad honorem y censura el plural latino ${ }^{\otimes} \mathrm{ad}$ honores marcándolo con bolaspa (la imposibilidad de ese plural probaría que la expresión tampoco es latina del todo). Algo parecido sucede con la locución [persona] non grata, que según el diccionario es válida solo en femenino y en singular; afirma que no es admisible el uso de $\otimes$ non grato como adjetivo masculino, ya que mezcla el adverbio latino non y el adjetivo español grato (en latín sería gratus); debe usarse la locución completa persona non grata, o bien la equivalencia española no grato; el DPD marca con bolaspa el plural ${ }^{\otimes}$ personas non gratas. También se ha lexicalizado en español la locución adjetiva sine qua non, que mantiene invariable el femenino qua (en latín referido al femenino condicio), tanto si se vincula a sustantivos femeninos como masculinos. Creemos que toda esta casuística refleja que las locuciones de las que hemos hablado no están nada integradas en español, sino que se usan como citas del latín; en nuestra opinión, el resalte tipográfico en estos casos sería imprescindible.

\section{RECOMENDACIONES SOBRE GRAFÍA Y PRONUNCIACIÓN}

No vamos a detenernos en las indicaciones sobre la acentuación de los latinismos, para los que el $D P D$ propone seguir las reglas generales, algo que ya hacen las obras lexicográficas recientes, tanto académicas como extraacadémicas.

Pasamos a estudiar las recomendaciones sobre grafías. En principio, el criterio para los latinismos es el mismo que para los extranjerismos: se censuran siempre las grafías semiadaptadas o híbridas, por no ser voces «ni latinas ni españolas» (así ${ }^{\otimes}$ acuárium o ${ }^{\otimes}$ estádium, con $c$ y $e$ protética pero final en - um), y también las grafías no adaptadas (como ${ }^{\otimes}$ addenda $\mathrm{o}{ }^{\otimes}$ affidavit, con grafía doble) o desusadas (como harmonio /-ium, con $h$ inicial). En cualquier caso, se sigue el criterio de vigencia en el uso general culto en otras voces como álbum, latinismo asentado con su terminación $-m$ desde antiguo (se censura ${ }^{\otimes}$ álbun). En ocasiones, la forma etimológica de algunas palabras choca con la más usual, y el $D P D$ manifiesta la preferencia por esta última: así, recomienda la variante fisonomía, por ser más usada en la actualidad, mejor que la forma fisionomía más cercana al étimo latino.

Sin embargo, encontramos muchos ejemplos en que los criterios citados no se siguen. Es únicamente la fidelidad a la etimología lo que parece haber guiado las siguientes recomendaciones: la preferencia por peccata minuta con $c c$ (censura ${ }^{\otimes}$ pecata con una) y por súmmum

${ }^{10}$ Es distinta la razón por la que se censura el alma máter, expresión en la cual se ha confundido el latín alma con anima, y de ahí el uso del artículo el delante del supuesto sustantivo femenino que empieza con $a$ tónica; en realidad, alma es la forma femenina del adjetivo latino almus 'nutriente, que alimenta', por lo que la construcción correcta es la alma máter. 
con $m m$ (se admiten las dos variantes, súmmum y súmum, pero se prefiere la grafía doble, súmmum, que es la forma que da entrada al artículo correspondiente); lo mismo sucede con la forma etimológica ex cáthedra con th, mejor que la grafía hispanizada ex cátedra, o también con la grafía etimológica deus ex máchina, cuya ch no se corresponde en absoluto con la pronunciación. ${ }^{11}$ Otros casos de respeto a la forma etimológica serían casus belli con $l l$, sanctasanctórum con el grupo nct o post scríptum con $s$ líquida, en lugar de las adaptaciones *casus beli, * santasantórum o * post escríptum, acordes con la pronunciación.

En cuanto a las formas terminadas en $-m$, final extraño en español, el criterio no es nada uniforme. El $D P D$ recomienda ínterin (censura la forma etimológica ${ }^{\otimes}$ interim), pero no aplica la misma regla a ítem, ibídem o ídem, que aparecen con $\mathrm{su}-m$ final etimológica; si el criterio fuera el de mayor o menor integración, al menos ítem sí debería llevar $-n$. Por otra parte, prefiere la grafía con $-n$ final para súmun, aunque admite súmum, pero censura este mismo final en ${ }^{\otimes}$ álbun, a pesar de que es la pronunciación que se recoge como habitual en el uso culto en la Gramática de Alarcos (1994). Tampoco propone cambiar esta -m final en muchos otros casos: currículum, presidium, critérium..., y la mantiene también en extranjerismos de otras procedencias, como tándem.

Por lo que se refiere a la grafía que refleja la labiovelar latina, recomienda la variante adaptada $c$ en vez de la etimológica latina qu para cuadrivio, preferible a quadrívium, o acuario en vez de ${ }^{\otimes}$ aquárium, pero sigue un criterio etimológico, a pesar de ser contrario al uso, para quídam (aun cuando recomienda pronunciar cuídam), exequátur o quórum; lo esperable, en este caso, sería encontrar recomendadas las grafías con $c^{*}$ cuídam, *execuátur o *cuórum.

En cuanto a las recomendaciones sobre pronunciación, el $D P D$ admite la pronunciación culta latinizante o la hispanizada para la qu de quid (/kuid/o/kid/), y también las dos pronunciaciones para la $c$ de sub iúdice (con oclusiva/yúdike/ o con fricativa /yúdi $\theta e /)$; sin embargo, solo admite la pronunciación latina para quídam o quid pro quo, y paradójicamente recomienda la pronunciación hispanizada con la fricativa interdental $/ \theta$ / para íncipit (aunque dice también que es frecuente oír la pronunciación latinizante /ínkipit/, sin valorarla). Suponemos que cuando afirma que «la pronunciación que le corresponde en español es [ínsipit, ínzipit]» se refiere a la alternancia propia de zonas seseantes / no seseantes. Por otro lado, considera correctas tanto la pronunciación clásica como la vulgar para el diptongo latino ae (en lapsus /línguae/ o /língue/y currículum /bítae/o /bite/); sin embargo, censura la pronunciación latinovulgar con fricativa palatal sui /yéneris/y recomienda la hispanizada con fricativa velar sui /xéneris/, sin advertir nada de la pronunciación clásica con oclusiva velar sui /géneris/. Respecto al latinismo júnior, considera que debe pronunciarse con la velar $/ x$, conforme a la escritura, no con la palatal (/yúnior/), aunque dice que está muy extendida esta pronunciación inglesa; esto choca con la recomendación para la expresión sub iúdice, en la que se considera mejor la pronunciación con palatal $/ y /$

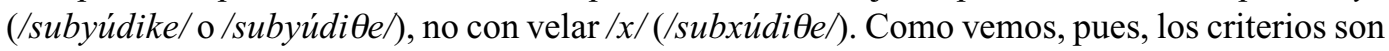
bastante diferentes en unas $\mathrm{u}$ otras palabras y no se ajustan totalmente a las grafías propuestas. ${ }^{12}$

${ }^{11}$ Nótese el efecto que produce el contraste entre la grafía latinizante y la adaptación a las reglas generales de acentuación en español.

${ }^{12}$ Las mismas arbitrariedades que hemos señalado en el tratamiento de los latinismos se pueden apreciar también en las recomendaciones para otros préstamos, cuyo estudio detallado excede los límites de este trabajo. Citaremos algunos ejemplos: desaconseja, por minoritaria, la adaptación ${ }^{\otimes}$ debú (propone debut, sin cursiva), pero adapta (con redonda) balé, esprín, baipás o afer (que corresponden a ballet, sprint, by-pass o affaire); propone adaptaciones (en redonda) comojipi o zum, pero recomienda la grafía hándicap y no *jándicap a pesar de la pronunciación; propone la adaptación de freezer en frízer (con redonda), pero no en *frícer, que sería más acorde con la ortografía del español. 


\section{FORMACIÓN DE PLURALES}

Nunca han ofrecido problemas las palabras con finales en vocal, que adoptan la terminación $-s$, al igual que las voces patrimoniales (etcétera, pl. etcéteras; desiderata, pl. desideratas); el problema se encuentra en los términos que ofrecen dificultad de acomodación por presentar finales en consonantes como $-m o-t$, ajenos al sistema fonológico del español. Lo normal sería que adoptaran un plural en -es, análogo al de otros finales consonánticos (*vademécumes, *curricúlumes o *accésites), pero esto, según el Esbozo (1973:183), «produce una estructura insólita y desapacible para el oído español». Vamos a analizar las observaciones que encontramos en diversas gramáticas respecto a estos términos de pluralización difícil. El criterio del Esbozo, en lo que se refiere a los posibles plurales de los latinismos, es muy vago:

Para los neutros griegos y latinos podría recomendarse el plural en - $a$, que se ha usado aisladamente alguna vez. [...] De hipérbaton se ha empleado el plural anómalo hipérbatos, más respetable que hipérbatons. Otros [...] se emplean pocas veces en plural, y cuando se emplean, pueden muy bien quedar invariables [...], que es lo que se hace muchas veces al pronunciarlos. Los plurales armoniums, máximums, mínimums y médiums, no infrecuentes en textos literarios, deben desecharse, existiendo como existen armonios, máximos, mínimos y medios. El plural de álbum es álbumes. ${ }^{13}$

Hemos destacado en negrita las expresiones que mejor reflejan la vaguedad en los criterios que guían las recomendaciones del texto académico (que ciertamente parece tener, en estas líneas, más voluntad prescriptiva que descriptiva, a pesar de su declaración inicial de intenciones). A un hablante interesado en construir bien el plural de palabras que sí se emplean con frecuencia, como currículum o accésit, le resultaría difícil saber qué solución adoptar.

En la Gramática de la lengua española de Alarcos (1994: 64) se distinguen varias soluciones para estos plurales: los cultismos recientes y poco difundidos presentan /s/ (desiderátums), o adoptan en la lengua escrita y culta el significante plural originario (desiderata) o quedan invariables (los memorándum); los que se han generalizado en el uso se adaptan al esquema normal (álbumes, hipérbatos, currículos, ${ }^{14}$ simposios). Como veremos, estas recomendaciones chocan con las del DPD.

En el capítulo dedicado a la flexión de número, dentro de la Gramática descriptiva de la lengua española de Bosque y Demonte, Ambadiang (1999: 4896) se hace eco de la complejidad de la pluralización de los préstamos y la falta de criterio uniforme respecto a ellos. En definitiva, viene a coincidir con todas las gramáticas descriptivas en que los préstamos que no están totalmente integrados no admiten la terminación - es que les correspondería (con la excepción de álbum / álbumes), sino que prefieren la marca $-s$ o la ausencia de morfema de número; algunas recogen para los latinismos la posibilidad de construir un plural en $-a$, de acuerdo con las reglas de la morfología latina.

Los diccionarios del español (DRAE, DEA, DUE, Salamanca) presentan un panorama similar al de las gramáticas y recomiendan los plurales en $-S$ o sin marca para estas palabras;

${ }^{13}$ Los latinismos que cita son, además de los que se encuentran en el fragmento recogido, los siguientes: desiderátum, memorándum, réquiem, déficit, superávit, quantum, exequátur, fiat, plácet, quorum, interin, tedéum y tuáutem.

14 «...de currículum, en lugar de currícula, se dice currículos». Sin embargo, no se marca como incorrecto el plural currícula; también sorprende que se admita el plural originario para desiderata, pero no para currícula. 
en algunos casos señalan la posibilidad de construir plurales en - $a$, según el modelo latino, sin que puedan entenderse muchas veces las razones por las que este plural es posible en unos términos y no en otros. Por ejemplo, Salamanca, s. v. memorándum o memorando, indica que el plural es memoranda o memorandos, pero en la entrada de referéndum o referendo señala referéndums o referendos, y en la de médium, marca la palabra como invariable (plural médium); para vademécum, no señala ningún posible plural. Por su parte, el $D E A$ indica que médium tiene plural en $-s$; vademécum, plural en $-s$ o invariable, lo mismo que referéndum; memorán$d u m$, plural invariable o en $-s$ (el cambio de orden parece sugerir que en esta palabra es más frecuente la invariabilidad que en vademécum o referéndum); no se señala forma de plural para pódium. Como vemos, es clara la falta de acuerdo en la pluralización de estos términos. En algún caso, el $D E A$ proporciona datos de uso que pueden ser significativos: por ejemplo, en la entrada correspondiente a referendo, ${ }^{15}$ este diccionario aclara que se usa generalmente en plural, lo cual puede señalar una tendencia que no parece haber triunfado en el proceso de adaptación de estos términos: uso de la forma con la terminación -um en singular / uso de la forma castellanizada en $-O$ para el plural.

Ya en un trabajo anterior (Azofra 1996) señalábamos la necesidad de que la Academia adoptara un criterio homogéneo y coherente para la acomodación de todas las voces terminadas en finales problemáticos, difíciles de adaptar a los patrones morfológicos del español. Ahora ya lo tenemos, gracias al $D P D$ : en el artículo dedicado al plural, en un apartado específico para los latinismos, este diccionario recomienda dejar invariables las locuciones latinas (los álter ego, los tótum revolútum, los delírium trémens, los currículum vítae...) y acomodar los plurales de los latinismos simples a las reglas de formación generales para los extranjerismos, dependiendo de sus características formales. De esta forma, tendríamos varias soluciones:

- Latinismos terminados en $-s$ : plural en -es para los monosílabos (plus, pl. pluses), plural invariable para los demás: lapsus, pl. lapsus; opus, pl. opus, exlibris, pl. exlibris.

- Latinismos terminados en $-r \mathrm{o}-n$ hacen plural en -es (nomenclátor, pl. nomenclátores). Excepciones: hipérbaton, pl. hipérbatos, y latinismos procedentes de formas verbales, para los que se señala plural invariable: los cónfer, los imprimátur, los confiteor, los exequátur. A veces, esta recomendación choca frontalmente con usos muy asentados: júniores en vez de ${ }^{\otimes}$ júniors.

- Quizá lo más novedoso sea la recomendación del plural en - s para los terminados en - $m$ y -t (los accésits, los déficits, los magníficats, los hábitats, los items, los vademécums...), aunque choque con recomendaciones anteriores y sea mayoritaria la forma invariable (los quórums, no ${ }^{\otimes}$ los quórum, los íncipits y los éxplicits, no ${ }^{\otimes}$ los íncipit $\mathrm{ni}{ }^{\otimes}$ los éxplicit $) .{ }^{16}$ No es extraño que el $D P D$ recomiende los finales en - ts o - $m s$, ajenos a la fonología del español, pues la incorporación de latinismos ha ampliado las posibilidades fonemáticas del español en otros momentos de la historia, y nunca parece haber sido un obstáculo la dificultad articulatoria para el mantenimiento de los grupos consonánticos cultos (combinaciones como $/ \mathrm{gn} /, \mathrm{ks} /, \mathrm{kt} / \mathrm{,} / \mathrm{ps} / \mathrm{l} / \mathrm{pt} / \mathrm{y}$ tantas otras). Una cuestión que el $D P D$ no entra a considerar es la pronunciación de estos elementos finales, que en la cadena hablada, por su dificultad articulatoria, pueden aparecer desprovistos de realización fonética (Ambadiang 1999:

${ }^{15}$ En el $D E A$, las variantes en - $O$ y en -um aparecen en dos entradas independientes.

${ }^{16}$ No se comprende bien por qué las formas verbales terminadas en $-r$ deben permanecer invariables mientras que las terminadas en $-t$ deben tomar la $-s$ de plural, aun cuando la dificultad articulatoria del grupo - $t s$ es mayor que la del grupo -rs. 
4898); si se mantiene la pronunciación de $-t$ o de $-m$, la $s$ puede perder relevancia, con lo cual podrían parecer formas invariables, a pesar de ser forzosa la marca en la escritura.

Creemos que el establecimiento de estas normas permitirá aclarar y poner orden en una cuestión que, como ya hemos dicho, era motivo de desacuerdos por parte de los gramáticos y de vacilaciones en los hablantes. Ahora bien, el $D P D$ añade dos recomendaciones un tanto arbitrarias y que, desde luego, no se ajustan al criterio de uso y vigencia de los hablantes cultos.

La primera de ellas sería la que aconseja usar con preferencia, cuando existan, las variantes hispanizadas de los latinismos: por ejemplo, armonio o podio (y sus correspondientes plurales armonios o podios) mejor que armónium o pódium. Como sabemos, las palabras son empleadas por el hablante no solo en función de su significado denotativo, sino que influye mucho el valor connotativo que llevan asociado; de esta manera, la fuerza evocadora de prestigio, de excelencia, que acompaña a una palabra como pódium no es comparable a la de podio; quizá por eso hemos podido oír recientemente a un joven deportista, poco sospechoso de emplear su tiempo en el estudio del latín, decir «Lo importante es que este año he hecho varios pódiums», con la forma en -um, a pesar de la dificultad de su plural.

Además, la adaptación del final latino - um en -o limita la posibilidad de crear dobletes semánticos, como podría ser currículum 'historial académico y profesional'/ currículo 'plan de estudios'; en este sentido, es interesante observar lo sucedido con el término currículo para referirse al plan de estudios: la tendencia a emplear currículum en esta acepción (algo que nunca han admitido los diccionarios académicos, pero sí otros como el $D E A$ ) es tan fuerte, sin duda por deseo del hablante de emplear una palabra sentida como más prestigiosa, que el $D P D$ se ve obligado a aclarar que es incorrecto currícula como sustantivo femenino para referirse al conjunto de los planes de estudios. ${ }^{17}$ Otros latinismos ya han creado estos dobletes con las formas en - um y en - $o$, de manera que recomendar la forma hispanizada daría lugar a posibles homonimias incómodas, como la que se establecería entre presídium y presidio, que ahora mantienen perfectamente delimitadas sus respectivas referencias: presidio 'encarcelamiento' / presídium 'órgano comunista' o 'estrado'; ${ }^{18} \mathrm{o}$ entre lapso 'intervalo de tiempo' y lapsus 'falta o equivocación que se comete por descuido'; entre medio 'situado a igual distancia de dos extremos' y médium 'persona con supuestas dotes de comunicación con los espíritus'; o entre criterio ‘juicio, opinión' y critérium para los significados de 'torneo deportivo no oficial' y 'tipo de carrera hípica'.

El deseo de mantener las dos variantes, para evitar una homonimia incómoda, es la razón por la que el $D P D$ recomienda conservar las formas en - um en la mayoría de los casos; sin embargo, otras veces estas mismas razones no se tienen en cuenta, como sucede con continuo, recomendado en vez de ${ }^{\otimes}$ contínuum, que aparece censurado a pesar de que se usa habitualmente como sustantivo en el sentido de 'serie o totalidad continua en la que ninguna de las partes se percibe como distinta'.$^{19}$ Es frecuente, en filología, hablar del contínuum dialectal, muchas veces escrito sin cursiva; por su parte, el CREA proporciona abundantísimos ejemplos de contínuum con este significado y otros semejantes: la recomendación del $D P D$, en este caso, deshace el doblete, crea una homonimia innecesaria y es contraria al uso. Por último, no faltan los casos en que el

${ }^{17} \mathrm{La}$ forma reanalizada como femenino solo puede explicarse por la frecuencia del plural currícula, censurado por el $D P D$.

${ }^{18}$ Por eso el $D P D$ desaconseja expresamente adaptar este latinismo en la forma presidio, que tiene significados tradicionales muy diferentes en español.

${ }^{19}$ Cf. DEA, s. v. contínuum. 
diccionario, a pesar de su preferencia por las formas hispanizadas, recomienda las variantes etimológicas por estar consolidadas en el uso culto; éste es el motivo de su recomendación para $u l$ timátum y vademécum, sin que pueda entenderse por qué no hace lo mismo para maremágnum, por ejemplo, sino que prefiere maremagno, un término mucho menos usual; o por qué se recomienda memorando en vez de memorándum. Hemos comprobado en el CREA que ninguna de estas variantes hispanizadas es más frecuente que la etimológica correspondiente; si acaso, se advierte una tendencia mayor a la hispanización de estos términos en el español de América; por ejemplo, referendo casi ha sustituido a referéndum en Hispanoamérica, pero no en España, donde la forma latinizada se sigue usando con frecuencia. ${ }^{20}$

Por otro lado, el DPD, en el artículo temático PLURAL, dice claramente que «No deben usarse en español los plurales latinos en - $a$ propios de los sustantivos neutros» (por ejemplo, ${ }^{\otimes}$ currícula, marcado con bolaspa como incorrecto); esta recomendación choca claramente con un uso asentado y respaldado por distintas gramáticas. En estos casos, la elección del hablante culto que sí conoce la lengua latina se inclina muchas veces por formar el plural con $-a$, e incluso por reconstruir la forma completa, como en el caso del plural ${ }^{\otimes}$ córpora sobre corpus. El hecho de que el $D P D$ considere que los latinismos deben escribirse con letra redonda, sin resalte tipográfico, parece contradecir la preferencia de muchos hablantes cultos, que emplean la expresión los corpora de forma habitual, y marcan con la cursiva (y muchas veces con la ausencia de tilde) el uso de un término que se emplea de forma consciente como citado de otra lengua. ${ }^{21}$ Lo mismo que hemos destacado sobre la homonimia incómoda entre $-o \mathrm{y}-u m$, cabría aplicarlo también a los plurales en - a y los singulares derivados por reinterpretación de la terminación como femenina (caso de desiderátum y desiderata).

Nos queda hacer una observación respecto a los plurales de latinismos terminados en $-m s$ y $-t s$. En el $D P D$, los diferentes usos se ilustran mediante citas, extraídas en su mayoría del CREA (Corpus de referencia del español actual) o del CORDE (Corpus diacrónico del español), y solo excepcionalmente se ofrecen ejemplos de otras procedencias. Los ejemplos inventados, en lugar de citas textuales, se reservan, dice el diccionario, para «algunos artículos temáticos o de especial complejidad» (p. XXVIII). No deja de ser significativo el hecho de que solo algunos de los plurales recomendados para latinismos terminados en $-m$ y en $-t$ estén ilustrados mediante ejemplos textuales, ${ }^{22}$ mientras que no se ofrecen ejemplos para muchos otros como afidávits, desiderátums, éxplicits, incipits, magníficats, péplums, quídams o sanctasanctórums.

\section{CONCLUSIONES}

Consideramos que la labor del $D P D$ ha sido muy positiva para la acomodación del grupo léxico que estudiamos, pero que no resuelve todos los problemas de su integración. No es raro encontrar casos de arbitrariedad en la aplicación de los criterios adoptados por el diccionario, tanto en las recomendaciones para los latinismos como en el caso de otros préstamos. La mayoría de las veces la razón está en la lucha entre el respeto a la lengua originaria y el uso

${ }^{20}$ En Hispanoamérica, esta tendencia a castellanizar los finales difíciles se aprecia también en otros casos: por ejemplo, magnífica, sustantivo femenino, en lugar de magnificat (cf. Salamanca, s. v. magnifica). Este americanismo no se recoge en $D R A E$.

${ }^{21} \mathrm{El} D P D$ atribuye a la influencia del inglés el uso de esta forma corpora, que aparece censurada con bolaspa.

${ }^{22}$ No contamos la forma álbumes, plural asentado desde hace tiempo en nuestra lengua. 
general culto, que puede estar muy asentado y ser acorde o contrario a la etimología; tampoco faltan casos en que el uso culto se ha regido por recomendaciones anteriores que ahora contradice el nuevo diccionario. A veces es el criterio etimológico el que se sigue para recomendar una grafía o una adaptación a los patrones morfológicos del español, a pesar de que se haya recomendado como norma general la preferencia por las formas hispanizadas.

Por otro lado, en nuestra opinión, el carácter de superestrato de la lengua latina respecto al español exige que estos préstamos tengan un tratamiento diferente al de otros extranjerismos. En el uso culto, la voluntad del hablante se inclina por dar a su mensaje un eco de prestigio que solo se consigue si estas voces no se hispanizan demasiado. El DPD, con sus recomendaciones, impide que el hablante culto pueda marcar, mediante resalte tipográfico, su empleo consciente y expresivo de estos términos como citas de una lengua de cultura; la censura de formas como córpora o contínuum por parte de un filólogo, por ejemplo, o el uso menos consciente pero tan evocador de pódiums por parte de un joven deportista son muestras de una expresividad limitada ahora por la norma académica. En definitiva, ese alarde cultista actual (si se quiere considerar así) es heredero de una tradición que en la lengua española comienza con Berceo y no ha hecho sino enriquecer nuestra lengua con aportaciones del latín en distintas épocas, para cubrir necesidades léxicas o estilísticas. La historia de la integración de estos términos en español es tan peculiar, que resulta difícil reducirlos a unos patrones comunes con los préstamos de lenguas modernas, ignorando las condiciones pragmáticas de su producción y la sensibilidad lingüística de los hablantes que los emplean.

\section{REFERENCIAS BIBLIOGRÁFICAS}

Alarcos Llorach, E. (1994): Gramática de la lengua española, Madrid, Espasa-Calpe.

Ambadiang, Th. (1999): «La flexión nominal. Género y número», en I. Bosque y V. Demonte, dirs., Gramática descriptiva de la lengua española, III: Entre la oración y el discurso. Morfología, Madrid, Espasa-Calpe, pp. 4843-4913 (especialmente 4896-4899).

Azofra Sierra, M. E. (1996): «Problemática de la integración de los cultismos en español actual», De Roma al siglo XX, Madrid, UNED, I, pp. 493-498.

(2006): «Consideraciones sobre el concepto de cultismo», Revista de Filología Románica, 23, pp. 229-240.

DEA. M. Seco, O. Andrés y G. Ramos (1999): Diccionario del español actual, Madrid, Aguilar.

DPD. Real Academia Española (2005): Diccionario panhispánico de dudas, Madrid, Santillana.

DRAE. Real ACADEMIA EsPaÑola (200122): Diccionario de la lengua española, Madrid, Espasa-Calpe.

DUE. M. Moliner (19982): Diccionario de uso del español, Madrid, Gredos.

Real ACAdemia Española (1977): Esbozo de una nueva gramática de la lengua española, Madrid, Espasa-Calpe.

Salamanca. J. Gutiérrez CuAdrado, dir. (1996): Diccionario Salamanca de la Lengua Española, Madrid-Salamanca, Santillana-Universidad de Salamanca.

SECO, M. (19869): Diccionario de dudas y dificultades de la lengua española, Madrid, Espasa-Calpe. 